\title{
A VIVÊNCIA DA MATERNIDADE DE MÃES DE CRIANÇAS COM AUTISMO
}

\author{
Luciane Najar Smeha* \\ Pâmela Kurtz Cezar
}

\begin{abstract}
RESUMO. O estudo teve como objetivo compreender como as mães de crianças com autismo vivenciam a maternidade. Participaram da pesquisa quatro mulheres com filhos na faixa etária infantil que apresentam diagnóstico de autismo. Os dados foram obtidos por meio de entrevistas semiestruturadas, realizadas individualmente e analisadas conforme a Análise Textual Qualitativa. Os resultados apontam que esta vivência é uma experiência desafiadora. Estas mulheres renunciam à carreira profissional, à vida social e às relações afetivas em prol dos cuidados maternos. Surgem com isso sentimentos como incerteza, tristeza e desamparo. Conclui-se diante disso que é necessário possibilitar a estas mães um espaço onde elas possam ser escutadas, trocar experiências e amenizar suas angústias. Por fim ressalta-se que a psicologia pode funcionar como rede de apoio a estas mulheres e contribuir para a preservação da saúde mental de famílias que possuem um componente com diagnóstico de autismo.
\end{abstract}

Palavras-chave: Maternidade; autismo; psicologia.

\section{THE LIVING OF MATERNITY WITH AUTIST CHILDREN MOTHERS}

\begin{abstract}
The study aimed at understanding how mothers of children with autism experience motherhood. Participants included four women with children who have autism diagnosis. Data were obtained through semi-structured interviews and analyzed individually as Qualitative Textual Analysis. The results point out that this experience is a challenging experience. These women will not pursue careers, social life and personal relationships in favor of maternal care. Some feelings arise with such uncertainty, sadness and helplessness. We conclude that it is necessary to enable these mothers a space where they can be heard, share experiences and relieve their distress. Finally it is emphasized that psychology can work as a network of support to these women and contribute to the prevention of mental health in families that have a component with a diagnosis of autism.
\end{abstract}

Key words: Motherhood, autism, psychology.

\section{LA VIVENCIA DE LA MATERNIDAD EN MADRES DE NIÑOS CON AUTISMO}

RESUMEN. El presente estudio tuvo como objetivo comprender como las madres de niños con autismo vivencian la maternidad. Participaron cuatro mujeres con hijos en la edad infantil que presentan diagnóstico de autismo. Los datos fueron obtenidos por medio de entrevistas semiestructuradas, realizadas individualmente y analizadas según el Análisis Textual Cualitativo. Los resultados apuntan que esta vivencia es una experiencia desafiadora. Estas mujeres renuncian a su carrera profesional, vida social y a las relaciones afectivas en Pro de los cuidados maternos. Surgen con eso sentimientos como incertidumbre, tristeza y desamparo. Se concluye delante de esto que es necesario posibilitar a estas madres un espacio donde ellas puedan ser escuchadas, cambiar experiencias y amenizar sus incertidumbres. Finalmente se resalta que la psicología puede funcionar como red de apoyo a estas mujeres y contribuir para la prevención en salud mental en las familias que poseen un componente con diagnóstico de autismo.

Palabras-clave: Maternidad; autismo en la infancia; psicología.

A vivência da maternidade constitui uma nova fase da vida da mulher. Neste estudo entende-se a maternidade como um comportamento social que transcende o aspecto biológico e se ajusta a um determinado contexto sócio-histórico (Badinter,
1985). Desde a gravidez acontecem mudanças na rotina da futura mãe, principalmente se for a primeira experiência de gestação, despertando com isso novos sentimentos, fantasias e expectativas. Dessa forma, já no momento do nascimento, há possibilidades de

\footnotetext{
Doutora em Psicologia pela Pontifícia Universidade Católica do Rio Grande do Sul. Professora Auxiliar do Centro Universitário Franciscano, Brasil.

\# Graduanda em Psicologia pelo Centro Universitário Franciscano-RS, Brasil.
} 
decepções causadas pelo contato com o bebê, pois existe uma distância entre o filho fantasiado e o filho real (Soifer, 1992; De Felice, 2000; Maldonado, 2002).

Os pais anseiam pela criança perfeita e saudável porque encontram no filho a possibilidade de concretizar seus sonhos e ideais; e quando o filho possui alguma limitação significativa, suas expectativas se fragilizam, já que a criança perfeita que lhes proporcionaria alegrias não nasceu (Meira, 1996; Jerusalinsky, 2007).

De acordo com Buscaglia (2006), deparar-se com as limitações do filho, em qualquer família, é sempre um encontro com o desconhecido. Enfrentar essa nova e inesperada realidade causa sofrimento, confusão, frustrações e medo. Por isso, exercer tanto a maternidade como a paternidade torna-se uma experiência complexa, e, mesmo existindo o apoio de inúmeros profissionais e outros familiares, é sobre os pais que recaem as maiores responsabilidades.

Atualmente, é possível encontrar diferentes etiologias, graus de severidade e características específicas ou usuais do autismo. Diante disso, caracteriza-se esse diagnóstico como um transtorno de início precoce, com causas diversas e que compromete o processo de desenvolvimento infantil (Facion, Marinho, \& Rabelo, 2002; Salle, Sukiennik, A. Salle, Onófrio, \& Zuchi, 2002; Klin \& Mercadante, 2006). De acordo com o DSM-IV-TR (Associação Psiquiática Americana [APA], 2002), o autismo está incluído entre os transtornos globais do desenvolvimento e caracteriza-se por comprometimento em três áreas do desenvolvimento: habilidades de interação social recíproca, habilidades de comunicação e comportamento, interesses e atividades com padrões restritos e repetitivos.

A conduta do autismo se caracteriza principalmente pela incapacidade de estabelecer um sistema adequado de comunicação com o meio social. Essa dificuldade de comunicação se deve ao atraso na aquisição da linguagem, ao uso estereotipado e repetitivo da fala e à falta de reciprocidade social e emocional que o autista apresenta em suas relações (Marcelli, 1998; Bosa, 2001; Facion et al., 2002).

As crianças com autismo encontram maior dificuldade em realizar as atividades ditas comuns, daí acentuar-se a necessidade de cuidados e a dependência para com os pais ou cuidadores. Dessa forma, para se adaptar às limitações e necessidades específicas da criança com autismo, a família necessita de constantes mudanças na sua rotina diária (Fávero \& Santos, 2005; Schmidt, Dell’Aglio, \& Bosa, 2007).
É possível considerar então que as características inerentes aos comportamentos autistas, somadas à gravidade desse transtorno, podem constituir estressores em potencial para os familiares (Schmidt \& Bosa, 2007). Diante disso, estudos estão evidenciando a presença de estresse em famílias de portadores de autismo, os quais também enfatizam o impacto que as crianças com este diagnóstico causam sobre seus familiares, devido ao tempo e energia que são necessários para dar conta da sobrecarga de cuidados exigida pela situação (Schmidt et al., 2007).

Diante dessas questões teóricas e de reflexões, principalmente, acerca do envolvimento materno, o objetivo maior deste estudo foi compreender como as mães de crianças com autismo percebem suas vivências com relação à maternidade, e, mais especificamente, elucidar os sentimentos que perpassam essa trajetória, desvelar as especificidades da rotina de cuidados com a criança autista e, por fim, compreender como o acesso à rede de apoio pode repercutir nas vivências da maternidade.

Para isso foram investigadas as histórias de quatro mulheres, abrangendo as suspeitas iniciais em relação ao autismo do filho, o momento da confirmação do diagnóstico, a realidade atual da criança e as expectativas das mães em relação ao futuro. Assim, nesta pesquisa, o intuito é contribuir para os estudos em psicologia e, a partir disso, pensar em estratégias práticas para melhorar a realidade em foco e assim minimizar a complexidade das vivências maternas.

\section{MÉTODO}

Nesta pesquisa adotou-se a abordagem qualitativa de cunho descritivo, que, conforme Martins e Bicudo (1994), refere-se ao tipo de investigação capaz de compreender e descrever de maneira mais abrangente os aspectos de cunho pessoal, os quais não podem ser precisados numericamente.

Participaram deste estudo quatro mulheres que têm filhos na faixa etária infantil, de 6 a 10 anos, com diagnóstico de autismo. A faixa etária das mães situase entre 32 e 39 anos e sua escolaridade é de nível médio ou superior completo. A escolha dessas participantes ocorreu por conveniência e por meio de indicações. Ressalta-se que as participantes são denominadas por P1, P2, P3 e P4, enquanto os filhos são apresentados por F1, F2, F3 e F4 respectivamente, para preservar suas identidades. No quadro a seguir é possível visualizar de maneira mais detalhada os dados de cada participante. 


\begin{tabular}{|c|c|c|c|c|c|c|c|}
\hline Mãe & Idade & Escolaridade & Estado civil & Ocupação & Idade do filho & $\begin{array}{c}\text { Tempo que sabe } \\
\text { do diagnóstico }\end{array}$ & Outros filhos \\
\hline P1 & 38 & $\begin{array}{c}\text { Superior } \\
\text { completo }\end{array}$ & Casada & Não trabalha & 10 anos & 8 anos & Não \\
\hline P2 & 39 & Médio completo & Separada & Não trabalha & 6 anos & 1 ano & Filho de 2 anos \\
\hline P3 & 32 & $\begin{array}{c}\text { Superior } \\
\text { completo }\end{array}$ & Casada & Não trabalha & 7 anos & 4 anos & Filho de 3 anos \\
\hline P4 & 33 & $\begin{array}{c}\text { Fundamental } \\
\text { incompleto }\end{array}$ & Casada & Não trabalha & 8 anos & 4 anos & $\begin{array}{c}\text { Filhas de } 12 \text { e } 2 \\
\text { anos }\end{array}$ \\
\hline
\end{tabular}

Quadro 1 - Dados dos Participantes.

Para a coleta de dados foram feitas entrevistas semiestruturadas, efetuadas individualmente, com duração de mais ou menos uma hora e em locais escolhidos pelas participantes. As entrevistas ocorreram entre os meses de julho e agosto de 2008, sendo gravadas em áudio e transcritas na íntegra. Posteriormente, o material foi destruído para garantir o sigilo profissional.

Os dados coletados foram posteriormente trabalhados conforme a Análise Textual Qualitativa, que visa a aprofundar a compreensão dos fenômenos investigados, possibilitando com isso a emergência de novos significados sobre $\mathrm{o}$ assunto em questão (Moraes, 2003).

O primeiro passo para a análise foi a unitarização do "corpus", em que se examinou detalhadamente o material, o qual foi fragmentado para se encontrarem as unidades constituintes. Com a desmontagem dos relatos, foi possível elencar várias unidades de base que, tendo relação entre si, serviram para a construção de subcategorias. A seguir estabeleceu-se relação entre esses elementos, o que resultou nas seguintes categorias finais: Vivências da maternidade; Suporte social; e Expectativas em relação ao futuro.

Esta pesquisa foi encaminhada ao Comitê de Ética do Centro Universitário Franciscano (UNIFRA) e por ele avaliada. Como o estudo envolve seres humanos, elaborou-se o Termo de Consentimento Livre e Esclarecido, que foi lido, aceito e assinado por todas as participantes, garantindo-se com isso sua participação voluntária no estudo.

\section{RESULTADOS}

$\mathrm{Na}$ análise da primeira categoria, que se refere à vivência da maternidade, é possível compreender que o momento da confirmação do diagnóstico de autismo do filho é crucial para a família, em especial para a mulher, pois, enquanto mãe, é ela que precisará se dedicar aos cuidados com a criança. Diante desse fato, ela se depara com inúmeros sentimentos, muitas vezes contraditórios e capazes de fragilizar sua vivência da maternidade.

Nas falas de todas as mães que participaram da pesquisa é perceptível que, antes mesmo da confirmação desse diagnóstico, elas já sentiam que o filho apresentava algo de diferente. Como mães, percebiam que os comportamentos da criança mostravam que algumas características não estavam conforme o esperado para a idade.

A suspeita em relação ao diagnóstico de autismo do filho pode ser observada na seguinte fala:

"Eu notei que a partir de dois anos e meio ele começou a ficar alheio às coisas. Chegávamos ele não respondia, saíamos também não respondia. Só sentado ele fazia este movimento e olhava pra mãozinha. Algo de errado existe" (P1).

Salienta-se então que as características do autismo podem surgir com mais frequência por volta dos 30 meses, quando a criança passa a ter comportamentos de intolerância a estímulos externos e mostrar atrasos significativos no tocante à aquisição da linguagem (Marcelli, 1998; Owen, 2007).

Logo após as suspeitas iniciais decorrentes dos comportamentos da criança vem a busca pela confirmação do que está acontecendo com o filho. Conforme Núñes (2007), quando as limitações do filho são evidenciadas, surgem nos pais sentimentos como ansiedade, desilusão, preocupação e culpa. As pesquisas de Welter, Cetolin, Trzcinski e Cetolin (2008) também indicam que os sentimentos mais comuns em mães que possuem filhos com alguma deficiência são tristeza, incerteza, inconformismo e culpa.

Verifica-se, na fala das entrevistadas, uma abrangência de sentimentos no que diz respeito à confirmação do diagnóstico. Cada mãe sentiu esse momento de forma bastante singular. Nos relatos a seguir, é possível entender os sentimentos que 
perpassaram esse momento; "Foi.. assim... chocante pra nós, nosso primeiro filho, esperado e tudo. Foi difícil. (P1). “(...) quando veio o diagnóstico eu fiquei arrasada, mas eu já tinha certa desconfiança, então pelo menos depois disso deu pra nortear um caminho a seguir" (P3).

Diante de sentimentos de choque, tristeza e até mesmo aceitação percebe-se que existem muitas incertezas em relação ao filho; por isso o momento da confirmação do diagnóstico traz mais dificuldades para algumas mães, enquanto para outras traz certo alívio, já que a partir desse momento será possível buscar o tratamento mais adequado para o filho.

Dessa forma, quando a criança idealizada se torna uma criança com autismo, os sonhos e expectativas que os pais projetavam em relação ao filho se fragilizam. Eles sabem que essa criança não irá corresponder completamente aos seus ideais e, além disso, deparam-se com a certeza de que sua vida, a partir desse momento, precisará ser modificada. Em relação a isso, Jerusalinsky (2007) afirma que a vivência da maternidade é afetada quando o filho apresenta alguma limitação significativa, pois a mãe percebe a diferença existente entre a criança esperada e a criança real. Ela sente esse filho como um desconhecido, surgindo-lhe então muitas dúvidas em relação a como cuidar dessa criança.

Em alguns relatos constata-se que perceber as características autistas no filho gera muita angústia nas mães. Elas conseguem visualizar o contraste existente entre o filho sonhado e o filho real e entendem que essa criança, em decorrência de suas limitações, não poderá ser conforme elas esperavam. Nas falas transcritas a seguir é manifesto que tanto a entrevistada P1 como a P3 fazem esse movimento de projeção em relação ao filho sonhado e de incertezas em relação ao filho real, com autismo:

\section{"Por ser o primeiro e menino, eu deposito uma expectativa muito grande no primeiro neto, o primeiro filho. Só que ele veio com todo esse tipo de problema" (P1).}

Após se dar conta de que o filho, em decorrência do autismo, apresentará muitos comprometimentos, as mães buscam por soluções, na tentativa de amenizar as sequelas da criança. Conforme Mannoni (1999) e Jerusalinsky (2007), os pais demandam incansavelmente diagnósticos, avaliações e indicações porque anseiam que seja "curado" o filho que apresenta algum comprometimento, pois a criança que não corresponde ao ideal fragiliza o narcisismo desses pais, já que o futuro sonhando por eles para o filho se apresenta no plano do improvável, conforme expressa a mãe P3:
“(...) eu penso no futuro sabe, eu sempre imaginei. Ah, porque agora olha só meu filho quando tiver treze, quatorze anos, as meninas vão ficar ligando (...) aquela coisa sabe (...) e não sei se isso vai acontecer".

O olhar do outro é mais um fator que influencia na vivência da maternidade. Ver que as pessoas ficam incomodadas com a presença da criança autista é sentido pelas mães como um gesto de preconceito. Em relação a isso, Mannoni (1999) afirma que qualquer ofensa ao filho é sentida pela mãe como se fosse dirigido a ela própria. É justamente por perceber a fragilidade do filho diante do social que as mães também se sentem fragilizadas. Discriminar, ter preconceito ou até mesmo olhar de forma diferente para a criança mobiliza na mulher a vontade de proteger cada vez mais esse filho que, para ela, é uma criança indefesa. Assim, é devido a essa maior necessidade de proteção que as mães dedicam-se integralmente à maternidade.

Nos relatos das mães, foi possível identificar que os cuidados com a criança autista são prioridade em sua rotina diária. Elas dedicam integralmente seu dia ao filho, por isso elas não podem trabalhar fora ou exercer outra atividade. Cabe salientar que nenhuma das mães entrevistadas está trabalhando no momento. A rotina de cuidados, segundo elas, é árdua, difícil e cansativa, conforme refere a mãe $\mathrm{P} 4$ :

"Eu fico pensando como é que eu consigo? Eu fico pensando, meu Deus (...) às vez eu tô morta de cansada, mas eu (...) parece que tem uma coisa dentro de mim assim que eu quero mais (...)".

Ademais, não é só a vida profissional que é deixada de lado, mas as relações sociais, e até mesmo as relações afetivas sofrem modificações em decorrência dos cuidados com o filho. Diante disso, Núñes (2007) afirma que a mãe dedica todo seu tempo e sua energia para cuidar do filho, sacrificando-se enquanto mulher e esposa. Nos relatos da mãe P2 e P3 é possível compreender essas transformações:

"Eu tinha um namorado, mas agora já não tô mais, é meio difícil eu ter tempo livre, porque é 24 horas (...). "Eu tô completamente alienada, eu perdi a minha vida social, meus amigos eu perdi todos, né(...)"

Outra questão que está atrelada ao autismo do filho é a percepção da vida por outro viés. Pode existir, em decorrência dessa situação, uma mudança 
de valores e, conforme Welter et al. (2008), muitas mães que conseguem superar o fato de ter um filho com alguma deficiência apresentam uma nova significação sobre essa situação. $\mathrm{Na}$ fala da entrevistada P4 é possível compreender esse movimento quando afirma:

“(...) eu aprendi muito tendo um filho especial. Eu vejo que nessa vida a gente não é nada (...). Eu dava importância pra joias, carro, roupa sabe, hoje eu vou te dizer, não dou importância pra mais nada. Nada, nada, nada"!

Ressalta-se ainda que essa trajetória não pode ser percorrida sozinha. As mães precisam contar com o auxílio de outras pessoas ou instituições para conseguirem dar conta da sobrecarga de cuidados com a criança autista. Dessa forma, ao analisar a segunda categoria percebe-se que as redes de apoio/suporte social atuam como auxílio a estas mulheres, ajudando-as a melhor viver a maternidade.

Conforme Sluzki (1997), a rede social se caracteriza por relações significativas que o sujeito estabelece com outras pessoas ou instituições. Por meio desse suporte social, é possível receber apoio emocional, cognitivo e até mesmo financeiro. De acordo com Castro e Piccinini (2002) e Núñes (2007), as redes sociais, como a família ampliada, a comunidade, a escola e a equipe de profissionais, são fontes de auxílio e informação diante das adversidades sentidas pelos pais em decorrência da situação limitante do filho

Conforme os relatos das mães entrevistadas, as relações familiares são a principal fonte de auxílio para elas nas adversidades que surgem em decorrência do autismo do filho. A família nuclear, composta pelo marido e outros filhos, fornece subsídios importantes que ajudam a mulher a suportar a intensa rotina de cuidados com a criança autista. Os maridos contribuem principalmente com o apoio econômico, uma vez que as mulheres renunciaram a sua carreira profissional. De acordo com Núñes (2007), enquanto a mulher fica em casa para cuidar do filho, cabe ao marido trabalhar fora e se encarregar do sustento financeiro.

Outra rede de apoio encontrada pelas mães é a presença de outros filhos junto à criança autista. As mães relatam que, após o nascimento do bebê, o filho autista melhorou significativamente. Segundo Núñes (2007), a relação entre irmãos é um importante recurso de socialização, pois possibilita trocas e interação. Por isso, conforme as entrevistadas P2 e P3,
“(...) depois que meu filho nasceu ele melhorou bastante [...] a relação dele com o pequeno é muito boa, brinca e tudo(...)". "É incrivel sabe, com o nascer do meu menino mais novo ele começou a interagir muito mais".

Cabe ressaltar que, na realidade das participantes da pesquisa, os avós também são figuras centrais no que se refere aos cuidados afetivos e suporte financeiro à criança autista. Para Castro e Piccinini (2002), os avós são considerados pelas mães como os principais provedores de apoio e auxílio diante da situação atípica da criança. A entrevistada P3 refere-se à importância dos avós:

“(...) inclusive a minha mãe e meu pai podem dar a entrevista junto porque eles são tanto pais quanto eu (...) e quem arca com as despesas são os avós (...) que nós não teria condições com o salário do meu marido".

Não obstante, apenas o apoio familiar não é suficiente quando a criança apresenta muitas limitações em decorrência do autismo. É necessário também um acompanhamento técnico abrangente, que englobe não apenas profissionais da saúde, mas também da área da educação. Assim, Doria, Marinho e Pereira (2006) relatam que, quando os pais buscam algum tratamento para seu filho, chegam sempre com um discurso perpassado por angústia e incompreensões. A primeira dúvida desses pais referese ao motivo pelo qual a criança desenvolveu tais sintomas e, depois, desejam saber o que é preciso fazer para mudar e curar seu filho.

Ao discorrer sobre o tratamento de crianças autistas, Owen (2007) afirma que é necessário um trabalho em equipe interdisciplinar, aliando a psicoterapia à farmacologia. $\mathrm{O}$ autor ressalta a importância da participação ativa da família nesse processo. Bosa (2006), por sua vez, afirma que o tratamento se torna eficaz quando a equipe técnica possui habilidades para trabalhar junto à família da criança autista.

Diante disso, é interessante salientar que a relação com a equipe de profissionais, nos casos estudados, não abrange um tratamento interdisciplinar. Nos relatos das mães é possível identificar que cada profissional que atende a criança autista trabalha isoladamente, não havendo troca de informações. É a mãe ou outro familiar que faz esse intercâmbio de notícias em relação aos tratamentos em prol do bemestar da criança.

O ambiente escolar é outra referência importante para os pais de autistas. Após a busca incansável por 
tratamentos para o filho, surge também a necessidade de integrá-lo à sociedade, e isso poderia ser favorecido pela entrada do filho na escola. De acordo com Jerusalinsky (2007), integrar a criança à comunidade é um momento gerador de crise, pois já nas primeiras saídas, em locais onde estão outras crianças, é perceptível para os pais o surgimento da rejeição social. Por isso o momento da entrada do filho na escola também materializa a questão da diferença e dos limites em relação à aprendizagem.

O preconceito em relação ao autismo é sentido pelas mães quando elas buscam uma escola para o filho. Existe muito receio em aceitar a criança autista e, por isso, as escolas fazem sempre algumas imposições. É possível verificar, pela fala da entrevistada P1, que, devido ao autismo do filho, a escola impôs algumas restrições para aceitar a criança:

\begin{abstract}
"Só aceitam o "Fl" com a condição que eu ficasse esperando. Então agora faz três anos que ele se encontra na escola. Eu largo ele na porta, espero todo o período (...), e qualquer eventualidade eu tô aqui".
\end{abstract}

É relevante acrescentar que duas crianças autistas estão estudando em turmas especiais. Uma delas está em turma de ensino regular, com acompanhamento de uma educadora especial que permanece na sala junto à criança durante o período das aulas, e a outra não está estudando no momento, já que a mãe a tirou da escola devido aos preconceitos que sofria. Ressalta-se também que, na cidade de Santa Maria, RS, até o momento das entrevistas, não existia nenhuma escola especializada ou associação para autistas e, talvez por isso, as mães se sentem sozinhas ao enfrentar esta vivência.

Conforme Schmidt e Bosa (2007), as escolas para educação especial exercem funções importantes não apenas para a criança, mas também para as mães. Esses locais atuam como redes de apoio, auxiliando os pais seja por meio de informação e orientação seja com atendimento psicológico individual ou em grupos.

Por fim, ressalta-se a importância do apoio religioso às mães de crianças com autismo, pois acreditar em Alguém superior torna a vivência da maternidade uma experiência mais tranquila. De acordo com Núñes (2007), além de Schmidt et al. (2007) e Welter et al. (2008), diante das incógnitas em relação ao diagnóstico do filho, a mãe busca novas maneiras para amenizar essa situação. Ela encontra na religiosidade uma importante rede de apoio e conforto em suas angústias, facilitando sua adaptação a essa situação adversa. Na fala da entrevistada $\mathrm{P} 1$, é possível compreender a importância da religiosidade quando ela afirma: “(...) uma coisa que acalmou bastante ele foi o centro espírita, tudo ajuda né (...) Todos os meios, os recursos que eu acho que vão bem pra ele".

Nesse viés, entende-se que as mães busquem o que for preciso para ajudar o filho e amenizar suas angústias. Percebe-se então que o apoio familiar, o apoio técnico e o suporte religioso constituem uma rede social mais eficaz para as mulheres, quando o filho possui algum comprometimento significativo.

Apesar de poder contar com todo o suporte social, a situação limitante do filho desperta nas mães muitas incertezas, principalmente em relação ao futuro da criança e a seu desenvolvimento. Diante disso, evidencia-se a terceira categoria, que engloba as expectativas das mães em relação ao futuro da criança autista, salientando os planos e desejos que estas mulheres possuem para o filho.

Nenhuma mãe pode prever o que irá acontecer com seu filho, mas quando ele não apresenta um comprometimento, é mais fácil imaginar o seu desenvolvimento. Apesar disso, o futuro da criança autista é sempre uma interrogação para os pais. Compreende-se, a partir dos relatos das mães, que o importante para elas é que o filho seja feliz, e o fato de eles serem ainda crianças parece ampliar as expectativas positivas com relação ao futuro. $\mathrm{O}$ fato de o filho apresentar um grau leve de autismo, conforme os diagnósticos médicos, faz com que as mães sintamse mais confiantes em relação ao tratamento e à melhora da criança, embora elas saibam que será preciso um trabalho prolongado, que engloba a intervenção da equipe técnica e o suporte familiar e comunitário.

Bosa (2006) chama a atenção para a importância de se diagnosticar precocemente o autismo, pois quanto mais cedo se começar o tratamento, melhor será o prognóstico da criança. Nos relatos das mães entrevistadas, percebe-se que as intervenções profissionais junto ao filho começaram por volta dos dois, três ou quatro anos.

O sentimento de incerteza sempre está presente. Não é possível prever o que irá acontecer com a criança em termos de desenvolvimento e aquisições, por isso a mulher terá dificuldades em realizar projetos para sua vida que vão além dos cuidados com o filho

Percebe-se que, com o crescimento do filho e os resultados eficazes dos tratamentos, as mães começam a olhar para outras dimensões de suas vidas. Por meio das intervenções profissionais, a criança autista começa a se desenvolver, mostrando pequenos sinais de autonomia e interesse pela escola. Com isso, 
algumas mães percebem que podem realizar outras atividades, uma vez que possuem uma rede de apoio para auxiliá-las nos cuidados com o filho:

\begin{abstract}
"Eu pretendo agora, inclusive vô fazê o concurso(...) então quero vê se começo a retomar um pouco da minha vida também, voltar a ter uma vida, fazer alguma coisa pra mim(...) pro mеи prazer, porque eи esqueci de mim, sabe?” (P3); “... eu pretendo voltar a trabalhar"'(P2).
\end{abstract}

Tanto a entrevistada P3 quanto a P2 pretendem retomar a vida profissional e social. Elas conseguem perceber os progressos do filho e por isso sentem que não precisam mais dedicar-se exclusiva e integralmente à maternidade. Não obstante, na fala da entrevista $\mathrm{P} 4$, verifica-se que esse processo não acontece, quando afirma:

\section{“(...) eu acho que vou ter que cuidar do " $F 4$ " o resto da vida, né, sempre ensinando (...) porque trabalhar, como é que eu vou trabalhar e dexar ele? (...) eu só quero trabalhar com o "F4"(...) o meu objetivo é esse, é ter saúde pra cuidar do "F4".}

Assim, é possível pensar que o único planejamento que a entrevistada P4 consegue fazer para o futuro é continuar cuidando do filho autista. Por isso, conforme Mannoni (1999), o destino da mãe em relação ao filho com alguma deficiência está traçado. A mulher entregará o que for preciso de si, sem nunca renunciar, pois, enquanto mãe, cabe a ela cuidar eternamente desse filho.

Compreende-se então que a vivência da maternidade, quando se tem um filho com autismo, torna-se uma experiência complexa e desafiadora para as mulheres, já que elas se deparam com o desconhecido e imprevisível. Para o futuro existem expectativas, porém muitas incertezas, e em decorrência disso, algumas mães podem ter mais dificuldades para planejar outras ocupações que não aquelas referentes aos cuidados maternos.

\section{CONSIDERAÇÕES FINAIS}

Conclui-se com esta pesquisa que as mães de crianças com autismo dedicam a vida aos cuidados com o filho, não encontrando tempo para exercer outra atividade, e que a vivência da maternidade é uma experiência difícil, já que envolve uma sobrecarga de responsabilidades para estas mulheres. A partir disso, surgem questionamentos acerca desse comportamento materno. É importante refletir até que ponto essa sobrecarga de cuidados é benéfica à saúde da mulher, da criança e até mesmo dos demais familiares, como o marido e outros filhos, já que esses aparecem muito pouco na fala das mães e, elas os mencionam, sempre o fazem para estabelecer uma relação direta com o filho autista.

Constatou-se também a importância de uma rede social para estas mães. A qualidade do suporte advindo das redes de apoio torna a vivência da maternidade uma experiência menos sofrida, e quanto mais eficaz for o auxílio a estas mulheres, mais confiantes elas ficarão quanto aos cuidados com o filho autista. Salienta-se ainda que a ajuda, tanto emocional como financeira, recebida da família nuclear e ampliada, constitui a rede de apoio mais eficaz para estas mães.

Em face dos questionamentos referentes às práticas maternas, é necessário pensar o lugar da psicologia nessa situação. É preciso olhar não só para o autista, mas também para a família, principalmente para a mãe, já que é ela quem assume as maiores responsabilidades com o filho no que se refere aos cuidados básicos diários.

Diante disso, é preciso criar estratégias de intervenção e possibilitar a estas mulheres um espaço no qual elas possam ser escutadas, trocar experiências, compartilhar sua dor e sofrimento e amenizar suas angústias e incertezas. Neste contexto a psicologia pode funcionar como rede de apoio às mães e contribuir para a prevenção em saúde mental nas famílias que possuem membros com autismo. Como alternativas para melhorar a realidade pesquisada, propõe-se o desenvolvimento de grupos para pais baseados na troca de vivências, grupos informativos que auxiliem e orientem a família no trato com o autismo, assim como de grupos de sala de espera, enquanto a criança está em atendimento.

Por fim, ressalta-se que os questionamentos e inquietações sobre a vivência da maternidade de mães que possuem filhos autistas não se encerram com este estudo. Salienta-se a importância de investigações futuras sobre o autismo por meio de outros enfoques, não apenas referentes à maternidade. Como sugestão para outras pesquisas, é possível pensar em estudos acerca da paternidade, e até mesmo sobre quanto a relação conjugal é afetada quando se tem um filho com diagnóstico de autismo.

\section{REFERÊNCIAS}

Associação Psiquiátrica Americana. (2002). Manual Diagnóstico e Estatístico de Transtornos Mentais (4a ed. rev.). Porto Alegre, RS: Artes Médicas. 
Badinter, E. (1985). Um amor conquistado:O mito do amor materno. (5a ed). Rio de Janeiro: Nova Fronteira. (Original Publicado em 1980)

Bosa, C. A. (2001). As relações entre autismo, comportamento social e função executiva. Psicologia: Reflexão e crítica, 14(2), 281-287.

Bosa, C. A. (2006). Autismo: intervenções psicoeducacionais. Revista Brasileira de Psiquiatria, 28(1), 47-53.

Buscaglia, L. F. (2006). Os deficientes e seus pais: um desafio ao aconselhamento (5a ed.) (R. Mendes, Trad.). Rio de Janeiro: Record.

Castro, E. K., \& Piccinini, C. A. (2002). Implicações da doença orgânica crônica na infância para as relações familiares: algumas questões teóricas. Psicologia: Reflexão e Crítica, 15(3), 625-635.

De Felice, E. M. (2000). A Psicodinâmica do puerpério. São Paulo: Vetor.

Doria, N. G., Marinho, T. S., \& Pereira Filho, U. S. (2006). $O$ autismo no enfoque psicanalítico. Recuperado em 28 de março, de 2008, de http://www.psicologia.com.pt/artigos/textos.

Facion, J. R., Marinho, V., \& Rabelo, L. (2002). Transtorno autista. In J. R Facion (Org.), Transtornos invasivos do desenvolvimento associados a graves problemas do comportamento: Reflexões sobre um modelo integrativo (pp. 23-38). Brasília, DF: CORDE.

Fávero, M. A. B., \& Santos, M. A. (2005). Autismo infantil e estresse familiar: uma revisão sistemática da literatura. Psicologia: Reflexão e Crítica, 18(3), 358-369.

Jerusalinsky, A. (2007). Psicanálise e desenvolvimento infantil (4a ed.). Porto Alegre: Artes e Ofícios.

Klin, A., \& Mercadante, M. T. (2006). Autismo e transtornos invasivos do desenvolvimento. Revista Brasileira de Psiquiatria, 28(supl.1) Recuperado em 20 outubro, de 2008, de http://www.scielo.br/pdf/rbp/v28s1/a01v28s1.pdf.

Maldonado, M. T. (2002). Psicologia da gravidez: parto e puerpério (16a ed.). São Paulo: Saraiva.

Mannoni, M. (1999). A criança retardada e a mãe (5a ed.) (M. R. G. Duarte, Trad.). São Paulo: Martins Fontes.

Marcelli, D. (1998). Manual de psicopatologia da infância de Ajuriaguerra (5a ed.) (P. C. Ramos, Trad.). Porto Alegre: Artmed.
Martins, J., \& Bicudo, M. A. V. (1994). A pesquisa qualitativa em Psicologia: fundamentos e recursos básicos. São Paulo: Moraes.

Meira, A. M. (1996). Quando o ideal falha. In Escritos da criança $n$. 4. (pp. 67-69). Porto Alegre: Centro Lydia Coriat.

Moraes, R. (2003). Uma tempestade de luz: a compreensão possibilitada pela análise textual qualitativa. Ciência e Educação, 9(2), 191-211.

Núñes, B. A. (2007). Familia y discapacidad: de la vida cotidiana a la teoría. Buenos Aires: Lugar Editorial.

Owen, H. F. (2007). Autismo em neurologia infantil. In A. Jerusalinsky, Psicanálise e desenvolvimento infantil (4a ed.). (pp. 252-261). Porto Alegre: Artes e Ofícios.

Salle, E., Sukiennik, P. B., Salle, A. G. , Onófrio, R. F., \& Zuchi, A. (2002). Autismo infantil: sinais e sintomas. In W Camargos Jr. (Org.), Transtornos invasivos do desenvolvimento (pp. 203-209). Brasília, DF: Terceiro Milênio.

Schmidt, C., \& Bosa, C. A. (2007). Estresse e auto-eficácia em mães de pessoas com autismo. Arquivos Brasileiros de Psicologia, 59(2), 179-191.

Schmidt, C., Dell’Aglio, D., \& Bosa, C. A. (2007). Estratégias de coping de mães de portadores de autismo: lidando com as dificuldades e com a emoção. Psicologia: Reflexão e Crítica, 20(1), 124-131.

Sluzki, C. (1997). A rede social na prática sistêmica: alternativas terapêuticas. São Paulo: Casa do Psicólogo.

Soifer, R. (1992). Psicologia da gravidez, parto e puerpério. (6a ed.) (I. V. Carvalho, Trad.). Porto Alegre: Artes Médicas.

Welter, I., Cetolin, S. F., Trzcinski, C. \& Cetolin, S. K. (2008). Gênero, maternidade e deficiência: representação da diversidade. Revista Textos e Contextos, 7(1), 98 - 119.

Recebido em 03/08/2009 Aceito em 14/01/2011
Endereço para correspondência: Luciane Najar Smeha. Rua Roberto Severo Neto,75, Bairro Medianeira, CEP 97015-580, Santa Maria-RS, Brasil.E-mail: lucianenajar@yahoo.com.br. 